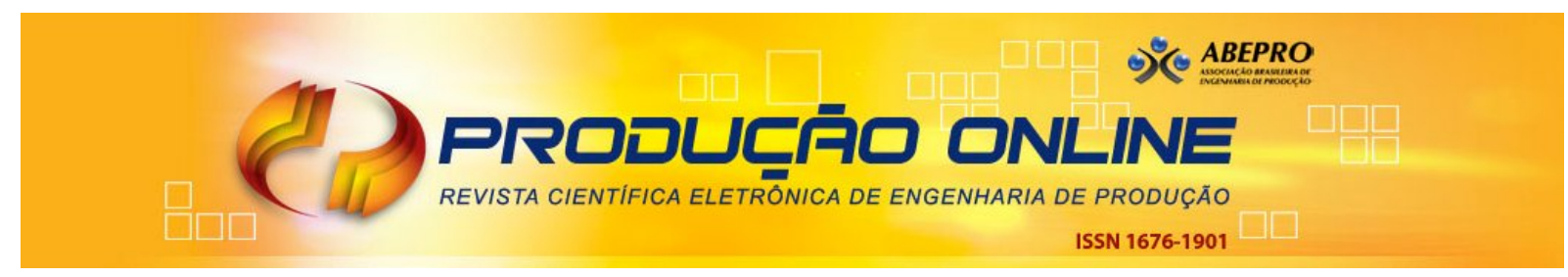

\title{
OBTENÇÃO DO NÍVEL DE ATENDIMENTO DE COMPETÊNCIAS DE ALTO VALOR
}

\section{MEASURING HIGH VALUE SKILLS LEVEL}

\author{
David Brandão Gonzaga* E-mail: brandao.david1@gmail.com \\ Jorge Muniz Júnior* E-mail: jorgemuniz@feg.unesp.br \\ *Universidade Estadual Paulista (UNESP), Guaratinguetá, São Paulo
}

\begin{abstract}
Resumo: Este trabalho tem como objetivo apresentar um método de obtenção do nível atingido das competências consideradas de alto valor para uma organização com três unidades de produção em países distintos. Para tanto, tem-se o seguinte questionamento: como obter o nível de atendimento das competências de forma a proporcionar ao gestor um panorama realista para a tomada de decisão? Deste questionamento, surge a hipótese de que, com a utilização de Survey estruturado e direcionado às competências de alto valor para a organização, o gestor pode obter informações relevantes para definir suas ações junto aos seus ativos humanos, seja para recompensar as pessoas de forma adequada, desenvolver as capacidades que podem definir o sucesso do negócio e também obter um panorama real e orientado dos principais gaps de competências. Utilizando a pesquisa bibliográfica, pôde-se verificar não apenas a visão de vários autores a respeito da importância do atendimento das competências bem como a forma de obtenção do nível de atendimento delas em um âmbito empresarial. Também com um modelo de Survey, dados sobre o atendimento das competências de alto valor para a empresa pesquisada foram obtidos e analisados.
\end{abstract}

Palavras - chave: Gestão. Competências. Competências organizacionais. Survey. Estratégia.

Abstract: This paper aims to present a measure method for the competences considered of high value for an organization which has three production units in different countries. Therefore, the following research question is proposed: how to get the level of the competences in order to provide a realistic panorama for management decision making? From that it arises the hypothesis that by using a structured survey targeted at high-value skills to the organization the manager can obtain relevant information to define their actions with their human assets, such as rewarding them adequately, developing the capacities that can define business success and, also providing a true picture of the main competences gaps. Through a literature review, it was possible to identify the importance of addressing the competences as well as how to improve theservice level in a business context. Finally, with a Survey model, data regarding the achievement of high-value competences to the researched company was obtain and analyzed.

Keywords: Management. Competences. Organizational competences. Survey. Strategy.

\section{INTRODUÇÃO}

Conforme Pépiot et al. (2008), não apenas os aspectos operacionais precisam ser levados em conta para a obtenção de vantagem competitiva, bem como a importância tática e estratégica das competências necessárias para o desempenho 
da organização. Pela dificuldade de obter as competências e transferi-las, vários modelos são discutidos, conforme apregoam vários autores tais como: Torres, Ziviane e Silva (2012), Maciel e Camargo (2009), Brandão e Guimarães (2001) e Brandão e Bahy (2005), passando pelo mapeamento de competências até a discussão da eficácia de algumas das competências, principalmente as de liderança (DRAGANIDIS E MENTZAS, 2006; CHUNG-HERRERA, ENZ E LANKAU, 2003). Kayakutlu e Büyüközkan (2010) compartilham a ideia de que as competências bem identificadas e avaliadas garantem o sucesso coletivo por meio do desenvolvimento de resultados da equipe e garantem o sucesso individual mediante 0 desenvolvimento dos envolvidos no processo produtivo. As competências denominadas de alto valor são as mais impactantes na decisão dos gestores, visto serem elas que geram altos ganhos e posicionamento estratégico, principalmente na área da inovação (FLEURY, FLEURY e BORINI, 2013).

Uma das preocupações quando se adota um programa de gestão de competências é o processo de obtenção e transmissão de competências, sendo que este processo é inteiramente baseado na confiança. Malmström, Wincent e Johansson (2013) postulam que, somente por meio da confiança e do compromisso mútuo, a organização pode usufruir da flexibilidade e da velocidade cada vez mais exigidas pelo mercado, já que estas podem afetar significativamente o desempenho financeiro das empresas.

Maciel e Camargo (2009) afirmam que as competências essenciais envolvem várias competências funcionais que por consequência, envolvem outras competências individuais. A exemplo, cita-se que o desenvolvimento da competência excelência em serviços envolve habilidades e conhecimentos em marketing e, também, gestão de pessoas (TOLEDO et al, 2008).

Este trabalho tem por objetivo apresentar uma metodologia para a obtenção dos níveis de atendimento das competências consideradas de alto valor para uma organização, especificamente, por meio do método de Survey difundido por Schuman e Kalton (1985). Pretende-se, também, por meio da pesquisa bibliográfica, não só referenciar a gestão por competência e seu valor para as organizações, bem como a apreciação dos estudos na área da gestão de competências para embasamento do instrumento de pesquisa utilizado. 
O presente trabalho está estruturado nas seguintes seções: gestão por competências na visão de vários autores da área de gestão, mapeamento das competências de alto valor para as organizações e seus principais métodos, método de pesquisa adotado para o levantamento das competências de alto valor, amostragem e seus critérios, resultados e considerações finais, a serem dissertadas a seguir.

\section{GESTÃO POR COMPETÊNCIAS}

Esta seção discute os artigos analisados no âmbito da gestão por competências. Pode-se observar que os artigos apresentados por Lima e Lezana (2005), Brandão et al. (2008), Maciel e Camargo (2009), Kayakutlu e Büyüközkan (2010), Fleury, Fleury e Borini (2013), Brandão e Guimarães (2001), Pépiot et al.(2008), Brandão e Bahry (2005), Christensen (1997), Malmström, Wincent e Johansson (2013) foram devidamente pesquisados, adaptados, classificados e registrados no Apêndice $A$.

Competências podem ser definidas como conhecimentos, habilidades e capacidades mensuráveis relacionadas ao ser humano dentro de um contexto específico de negócio, englobando as atitudes e o comportamento do indivíduo (DRAGANIDIS E MENTZAS, 2006). Dentro desta visão, pode - se verificar que todo desempenho considerado competente precisa possuir três elementos essenciais: capacidades, resultados e objetivos.

Bernardoni (2010) afirma que o conjunto de conhecimentos, habilidades e atitudes interdependentes e necessárias à consecução de determinado objetivo foi, durante muito tempo, denominado de "capacidades".

Os termos, conceituados pelo referido autor, quando se observa a palavra "interdependente" consideram-se os elementos distintos que se inter-relacionam entre si de modo que o todo se torne mais importante que a somatória das partes de forma independente (COVEY, 1989). Já conhecimentos são defendidos como uma fonte poderosa de poder e, também, a chave para as futuras mudanças (NONAKA, 2007).

Quanto às habilidades, elas podem ser definidas como a capacidade de "saber fazer". Dentro deste conceito, nas organizações, não basta apenas saber, 
mas também saber executar as atividades com excelência e de acordo com os objetivos da empresa. Saber fazer vai além do simples executar. Brandão e Guimarães (2005) reforçam que as habilidades fazem parte de uma combinação sinérgica, manifestas pelo desempenho profissional em determinado contexto e em determinadas estratégias organizacionais. Partindo deste pressuposto, as habilidades são tão importantes quanto conhecimento e atitudes, pois contribuem para o alcance da estratégia da organização.

Ajzen (1991) define atitude como uma predisposição para responder de forma favorável ou desfavorável a um objeto, pessoa, instituição ou acontecimento. Ainda segundo este autor, atitudes são crenças comportamentais, sendo elas de caráter normativo e as quais conduzem o comportamento. As atitudes dentro das organizações são um tanto importantes, pois provocam uma melhoria no desempenho dos profissionais (BERNARDONI, 2010).

O estudo das competências organizacionais vem sendo bastante utilizado por pesquisadores de várias áreas do conhecimento científico, como verifica-se no levantamento apresentado no Apêndice A.

\subsection{Mapeamento de Competências}

Em se tratando de melhoria nos processos, sejam vinculados à competitividade e à permanência no mercado, o mapeamento de competências oferece forte apoio, proporcionando ao gestor a possibilidade de tomada de decisões estratégicas e de manter uma visão compartilhada das competências e das metas da organização, servindo como guia e referencial para suas ações (TORRES, ZIVIANI e SILVA, 2012).

Amaral et al. (2008) afirmam que um dos primeiros passos para a implantação da Gestão por Competências em uma organização consiste na realização do mapeamento das competências, que servirá de base para o processo de Gestão por Competências.

O mapeamento de competências pode ser definido como a atividade de identificar quais os conhecimentos, as habilidades e as atitudes que são essenciais para o desenvolvimento do negócio, de modo que por meio delas, as organizações consigam atingir seus objetivos (BRANDÃO E GUIMARÃES, 2001).

Revista Produção Online, Florianópolis, SC, v.16, n. 1, p. 151-181, jan./mar. 2016. 
Já Brandão e Bahry (2005) mostram algumas técnicas de mapeamento de competências, conforme quadro 1 a seguir:

Quadro 1- Técnicas de Mapeamento de competências e descrição:

\begin{tabular}{|l|l|}
\hline \multicolumn{1}{|c|}{ TÉCNICA } & \multicolumn{1}{c|}{ DESCRIÇÃO } \\
\hline Pesquisa Documental & $\begin{array}{l}\text { Pesquisa realizada em arquivos, fichas e outros documentos } \\
\text { relevantes, levando em consideração a missão, os objetivos e a } \\
\text { estratégia da empresa. }\end{array}$ \\
\hline Coleta de dados & Coleta de dados realizada com pessoas -chave da organização. \\
\hline Observação & $\begin{array}{l}\text { Verificação e constatação de um fato, podendo ser metódica e } \\
\text { planejada. }\end{array}$ \\
\hline Grupos focais & $\begin{array}{l}\text { Método de pesquisa qualitativo, livre de medidas numéricas e } \\
\text { análises estatísticas. }\end{array}$ \\
\hline $\begin{array}{l}\text { Questionários } \\
\text { Estruturados. }\end{array}$ & $\begin{array}{l}\text { Método de obtenção de dados por meio da interrogação aos } \\
\text { pesquisados. }\end{array}$ \\
\hline
\end{tabular}

Fonte: Adaptado de Brandão e Bahry (2005, p. 182)

A competência deve representar um comportamento esperado, utilizando - se de verbos que descrevam o objetivo de uma ação. Também é importante ressaltar que não só a condição em que um determinado comportamento ocorre, bem como o critério que mostra uma qualidade que satisfaça devem ser acrescentados. Construir descrições muito longas e frases que demonstram duplo sentido na descrição das competências podem causar confusões e induzir a erros pela falta de compreensão das pessoas. Também vale ressaltar que abstrações e utilização de verbos que não expressem ações concretas podem levar ao fracasso no mapeamento de competências (BRANDÃO E BAHRY, 2005).

Atualmente as organizações frente à globalização e à competição cada vez maior, na maioria dos estudos que abordam liderança e gerenciamento, retratam as competências essenciais aos indivíduos responsáveis pela gestão de alto nível. Essas competências precisam ser revisadas com a finalidade de se obter um paralelo entre as competências exigidas e as competências apresentadas pela organização (CARNEVALLI, 2015). O desenvolvimento de competências contribui para melhorar o desempenho das organizações, visto que, existem gaps entre as competências necessárias e as competências atuais da organização no que tange a estratégia. Desta forma, sugere-se estabelecer objetivos e metas a serem atingidos

Revista Produção Online, Florianópolis, SC, v.16, n. 1, p. 151-181, jan./mar. 2016. 
conforme a intenção estratégica da organização, sendo necessário realizar-se a identificação dos espaços entre as competências essenciais e a consecução desses objetivos (VILLARREAL e CERNA, 2008)

\subsection{Mapeamento de Competências na Empresa Estudada}

Utilizando-se a metodologia de coleta de dados por meio de pessoas - chave da organização, apresentada por Brandão e Bahry (2005), foram extraídas as competências para três unidades de produção em três localidades distintas: Brasil, Argentina e México. Devido à empresa pesquisada estar em processo de alinhamento entre suas unidades, a pesquisa trouxe um panorama bastante relevante referente à realidade organizacional de cada unidade de produção.

A base para seu mapeamento das competências foi o texto do planejamento estratégico 2010/2015. Comparando as frases objetivas constantes no planejamento estratégico com os comportamentos necessários para a execução e cumprimento do plano, extraíram-se nove competências elencadas a seguir:

1. agilidade e flexibilidade;

2. comprometimento;

3. trabalho em equipe;

4. liderança;

5. criatividade e inovação

6. gestão de recursos;

7. foco em resultados;

8. visão sistêmica;

9. visão estratégica.

Para se entender os valores das competências elencadas pela organização pesquisada, seguem as definições das competências conforme verificado na literatura sobre o assunto:

- Agilidade e flexibilidade: entende-se como capacidade de adaptar-se e tomar providências rápidas diante de problemas, obstáculos e conflitos, em busca de soluções eficazes. Quanto maior o nível de flexibilidade de um grupo, maior é a disposição na aceitação de responsabilidades (MANTILLA e GARCIA, 2010). 
- Comprometimento pode ser definido como a capacidade de disponibilizar todo o potencial em prol dos objetivos e metas da empresa, colaborando e dando suporte com dedicação e empenho. De acordo com Bastos (1993), altos níveis de comprometimento do indivíduo com a organização é algo altamente positivo ou benéfico para ambos.

- Trabalho em equipe pode ser entendido como a capacidade de se relacionar de forma construtiva com as demais pessoas, demonstrando consideração e respeito, promovendo cooperação e integração, com foco em benefícios mútuos, a fim de obter sinergia (COVEY, 1989).

- Liderança: de acordo com Amaral et al. (2008), pode ser conceituada como a catalisação das necessidades e expectativas organizacionais e grupais, que promovem a visão, direcionamento, motivação e comprometimento.

- Criatividade e inovação: definidas como a apresentação de novos padrões e ideias originais e soluções inovadoras para as situações do trabalho, tendo - se a percepção das oportunidades, a realização de analogias das situações aprendidas e, até mesmo, vivenciadas (AMARAL et al., 2008).

- Gestão de recursos: Fleury e Fleury (2003) definem recursos como ativos físicos, financeiros, intangíveis (marca, imagem), organizacionais (cultura organizacional, sistemas administrativos) e recursos humanos. A gestão inteligente desses recursos leva a empresa a criar vantagens competitivas.

- Foco em resultados: orientar ações segundo os objetivos traçados para o trabalho, sem desvios (AMARAL et al., 2008).

- Visão sistêmica: definida como o ato de identificar, entender e gerenciar processos inter-relacionados, sendo esta uma prática que contribui para a eficácia e a eficiência da organização de modo que ela atinja seus objetivos (SOUZA, FARIA NETO e MUNIZ JR, 2012).

- Visão estratégica: pode ser definida como a identificação e o desenvolvimento de soluções específicas e sistemas que agreguem e maximizem valor ao produto, visando criar sinergias que alavanquem 0 potencial competitivo das empresas (FLEURY e FLEURY, 2003).

As competências estratégicas possuem alto valor para as organizações (FERREIRA et al., 2006). Em estudo apresentado por Sordi e Contador (2005), as competências essenciais contribuem para aumentar o foco e consequentemente 0

Revista Produção Online, Florianópolis, SC, v.16, n. 1, p. 151-181, jan./mar. 2016. 
grau de competitividade da empresa, essas competências são comparadas a armas relevantes que dão vantagens competitivas nos campos escolhidos para competir em cada mercado.

Com base na definição acima citadas das competências, elaborou-se um questionário em que cada uma das competências representou quatro comportamentos observáveis, de modo que eles reflitam os pontos de vista encontrados na teoria e nas entrevistas realizadas com as pessoas-chave da organização, conforme se mostra a seguir:

Quadro 2 - Descrição das competências e dos comportamentos observáveis: (continua)

\begin{tabular}{|c|c|}
\hline \multirow{4}{*}{$\begin{array}{l}0 \frac{0}{0} \\
\frac{0}{0} \\
\frac{0}{0} \\
\frac{0}{0} \\
\frac{0}{0} \\
\frac{0}{x} \\
\frac{0}{x}\end{array}$} & $\begin{array}{l}\text { 1. É rápido em tomar decisões difíceis. Analisa os problemas e todas as } \\
\text { possibilidades atuando nas causas geradoras. }\end{array}$ \\
\hline & Tem facilidade em implementar ações com rapidez e qualidade. \\
\hline & $\begin{array}{l}\text { 3. Está disposto a mudar suas táticas e comportamentos. Entende que a mudança é } \\
\text { necessária e define quais são os objetivos a serem atingidos. }\end{array}$ \\
\hline & $\begin{array}{l}\text { 4. Pode facilmente adaptar - se a novas situações e condições, inclusive, mudança } \\
\text { de atividade, departamento, unidade e/ou país. }\end{array}$ \\
\hline \multirow{4}{*}{ 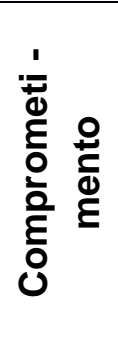 } & $\begin{array}{l}\text { 1. Assume responsabilidades como se fosse dono do negócio, inclusive, os sucessos } \\
\text { e fracassos. }\end{array}$ \\
\hline & $\begin{array}{l}\text { 2. Trabalha dedicadamente para atender às demandas e expectativas, inclusive, } \\
\text { aquelas relacionadas à mudança de atividade e localidade de trabalho. }\end{array}$ \\
\hline & 3. Demonstra ser uma pessoa ativa e participante, não mera expectadora \\
\hline & 4. Empenha-se ao máximo todo dia. \\
\hline \multirow{4}{*}{ 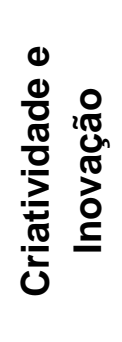 } & $\begin{array}{l}\text { 1. Encontra uma ideia rápida e interessante para solucionar o problema caso faltem } \\
\text { recursos durante a condução de uma atividade ou projeto. }\end{array}$ \\
\hline & $\begin{array}{l}\text { 2. Busca continuamente o aperfeiçoamento de suas atividades e a otimização de } \\
\text { recursos e processos. }\end{array}$ \\
\hline & Descobre novos recursos para resolver problemas. \\
\hline & 4. Aproveita as oportunidades para tornar os processos mais eficientes e eficazes. \\
\hline \multirow{4}{*}{ 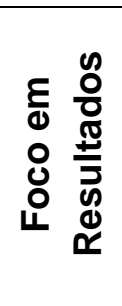 } & 1. Procura sempre cumprir prazos sem prejuízo da qualidade. \\
\hline & $\begin{array}{l}\text { 2. Organiza-se diretamente em torno de resultados que objetivem a satisfação do } \\
\text { cliente interno ou externo e não somente em torno de funções tradicionais. }\end{array}$ \\
\hline & $\begin{array}{l}\text { 3. Realiza suas atividades de maneira correta e alinhadas às estratégias da } \\
\text { organização. }\end{array}$ \\
\hline & 4. Procura começar projetos, atividades ou trabalhos com objetivo final em mente. \\
\hline
\end{tabular}

Revista Produção Online, Florianópolis, SC, v.16, n. 1, p. 151-181, jan./mar. 2016. 
Quadro 2 - Descrição das competências e dos comportamentos observáveis:

(conclusão)

\begin{tabular}{|c|c|}
\hline \multirow{4}{*}{ 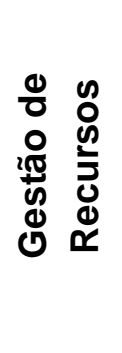 } & $\begin{array}{l}\text { 1. Gerencia prazos, custos e qualidade, garantindo a eficácia de suas ações e o } \\
\text { alcance dos objetivos econômicos da empresa. }\end{array}$ \\
\hline & $\begin{array}{l}\text { 2. Realiza o controle dos indicadores (parâmetros) buscando não só oportunidades } \\
\text { de redução de custos e outras despesas, bem como o aumento da produtividade. }\end{array}$ \\
\hline & $\begin{array}{l}\text { 3. Faz planejamento detalhado de cada etapa de suas atividades, especificando a } \\
\text { forma como os objetivos serão alcançados. }\end{array}$ \\
\hline & 4. Organiza e coordena todos os recursos à sua disposição. \\
\hline \multirow{4}{*}{ 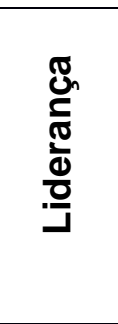 } & 1. Influencia e apoia as pessoas no desenvolvimento de competências. \\
\hline & $\begin{array}{l}\text { 2. Consegue apoio e envolvimento influenciando as pessoas com suas ideias e } \\
\text { comportamentos. }\end{array}$ \\
\hline & 3. Estimula as pessoas para enfrentarem desafios e superarem dificuldades. \\
\hline & $\begin{array}{l}\text { 4. Interfere no clima interno da equipe, sendo capaz de lidar com as adversidades e } \\
\text { eventuais conflitos de forma equilibrada, harmonizando o ambiente. }\end{array}$ \\
\hline \multirow{4}{*}{ 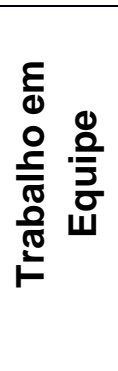 } & $\begin{array}{l}\text { 1. Consegue expressar suas ideias e pontos de vista de forma clara e direta, com } \\
\text { integridade e respeito aos outros, sem impor sua opinião. }\end{array}$ \\
\hline & 2. Ouve com atenção e procura compreender profundamente o outro. \\
\hline & $\begin{array}{l}\text { 3. Consegue o comprometimento da equipe com a obtenção dos resultados, de } \\
\text { forma que todos ganhem e criando um ambiente sinérgico, saudável e produtivo. }\end{array}$ \\
\hline & $\begin{array}{l}\text { 4. Colabora com as pessoas e auxilia na resolução dos conflitos, sendo agente } \\
\text { facilitador das relações entre elas. }\end{array}$ \\
\hline \multirow{4}{*}{ 蛋 } & $\begin{array}{l}\text { 1. Tem visão abrangente. Mantém-se atento à conjuntura que o rodeia. Percebe os } \\
\text { sinais de mudança e integra-os no âmbito de sua atuação. }\end{array}$ \\
\hline & $\begin{array}{l}\text { 2. Antecipa as necessidades de adaptação de suas atividades, define estratégias, } \\
\text { programa medidas e avalia os impactos das mesmas. }\end{array}$ \\
\hline & $\begin{array}{l}\text { 3. Alinha os objetivos de suas ações com os resultados a serem alcançados pela } \\
\text { organização. }\end{array}$ \\
\hline & Estabelece metas para suas ações e mensura sistematicamente o seu alcance. \\
\hline \multirow{4}{*}{ 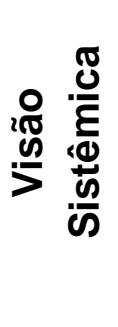 } & 1. Tem boa visão do todo. Não foca apenas suas atividades e departamento. \\
\hline & $\begin{array}{l}\text { 2. Identifica seus clientes e fornecedores internos e avalia adequadamente o impacto } \\
\text { de suas ações neles. }\end{array}$ \\
\hline & $\begin{array}{l}\text { 3. Conhece a realidade da empresa, consegue interpretar situações que podem } \\
\text { impactar positivamente ou negativamente nos resultados. }\end{array}$ \\
\hline & $\begin{array}{l}\text { 4. Avalia os impactos de suas ações em outras áreas ou processos, durante a } \\
\text { tomada de decisão. }\end{array}$ \\
\hline
\end{tabular}

Fonte: Autores

Segundo Günther (2003), para compreender o comportamento humano, pode -se utilizar de três ferramentas essenciais: (1) a observação que permite verificar o comportamento no âmbito real, (2) a simulação de um ambiente artificial e observação do comportamento frente às situações colocadas, (3) questionamento das pessoas sobre o que fazem e pensam.

Revista Produção Online, Florianópolis, SC, v.16, n. 1, p. 151-181, jan./mar. 2016. 
Resolveu-se adotar a terceira ferramenta proposta, pois, por meio de amostragem, pôde-se obter representatividade de toda a organização.

Após a definição dos comportamentos observáveis, criou-se um formulário totalmente novo, com pontuação para cada um dos comportamentos, conforme observado no quadro abaixo:

Quadro 3 - Pontuação e descrição dos critérios de avaliação:

\begin{tabular}{|c|c|}
\hline Pontuação & Descrição \\
\hline 1 ponto & Discordo totalmente \\
\hline 2 pontos & Discordo parcialmente; \\
\hline 3 pontos & Concordo parcialmente; \\
\hline 4 pontos & Concordo totalmente. \\
\hline
\end{tabular}

Fonte: Autores

O formulário foi devidamente carregado no Software HyperTextTransferProtocol, que, após o cadastro de todos os avaliadores, permitiu, por meio de e-mail, o recebimento dos formulários para preenchimento.

\section{MÉTODO DE PESQUISA}

O estudo apresentado tem por fim conhecer o nível de atendimento das competências denominadas de alto valor pela organização pesquisada. O objetivo está relacionado com a execução do planejamento estratégico pelas pessoas que compõem a organização, que determinam a competitividade da empresa, principalmente, frente ao desafio global de alianças estratégicas cada vez mais exigidas às indústrias frente à globalização (FLEURY, 1997).

Schuman e Kalton (1985) sugerem um modelo que serviu de base para a pesquisa em questão. A figura abaixo representa este modelo: 
Figura 1 - Estágios principais de um survey

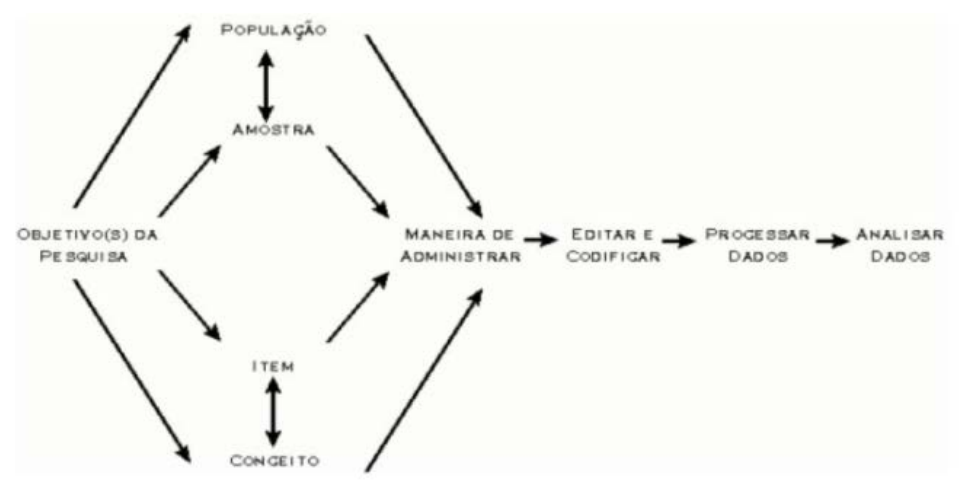

Fonte: Schuman e Kalton (1985)

\section{APLICAÇÃO DA PESQUISA}

Foram enviados 277 questionários, sendo 191 questionários para uma unidade da empresa pesquisada no Brasil, 51 questionários para a unidade do México e 35 questionários para uma Unidade na Argentina. A amostra foi determinada em função dos cargos considerados estratégicos e de alto valor pela empresa, sendo os sujeitos da pesquisa escolhidos devido ao grau de atendimento à estratégia e do novo perfil exigido pelo mercado.

Vieira e Garcia (2004) defendem que o novo ambiente empresarial é caracterizado por grandes mudanças, exigindo-se respostas cada vez mais ágeis e rápidas. Estas mudanças acarretam uma mudança significativa no perfil dos gestores e dos componentes das equipes de trabalho que as empresas buscam, dando início a um processo de reestruturação, o qual trouxe, por consequência, a redução de seus trabalhadores e a utilização dos benefícios de uma consultoria desenvolvida internamente. Essa decisão visava dar mais autonomia aos gestores, deixando-os cada vez menos dependentes dos órgãos de administração de pessoal, de modo que eles pudessem, enfim, realizar a gestão de suas equipes. Essa mudança gerou também a alteração do perfil do profissional de recursos humanos, tornando-o mais generalista e apto a desenvolver vários subprocessos de gestão de pessoas, com uma atuação mais proativa e um relacionamento mais fechado com os departamentos operacionais, que, por sua vez, constituíram-se em clientes internos do departamento de pessoal. 
Enquadrando-se no novo perfil dos gestores e dos profissionais, a amostra da pesquisa consistiu em três quesitos:

1. Cargos de Gestão (Diretores, Gerentes e Coordenadores);

2. Cargos essenciais ao Core Business da empresa (cargos especializados);

3. Engenheiros responsáveis pela interação cliente-empresa-produto.

De acordo com Günter (2003) o tamanho da amostragem é condicionado aos recursos disponíveis (tempo, dinheiro e recursos humanos), sendo estes fatores primordiais para as etapas de planejamento, codificação, processamento e análise dos dados.

A princípio, teve-se o cuidado de enviar primeiro para um grupo de avaliadores, fora do contexto oficial da pesquisa, a fim de calibrar o tempo, a facilidade de leitura, a pontuação, o envio correto da mensagem e a observação dos resultados gerados. O perfil dos avaliadores foi: um profissional de TI, um profissional de Engenharia da Qualidade e um profissional da área de Recursos Humanos. Todos os três avaliadores possuem mais de quinze anos de experiência na área em que atuam. Esta prática é incentivada conforme estudos realizados por Günter (2003).

\section{RESULTADOS}

Pode-se observar, no Gráfico 1, o nível de atendimento das competências denominadas de alto valor para a empresa estudada. Ainda no Gráfico 1, nota-se que a competência comprometimento atingiu maior pontuação dentre as demais $(83,1 \%)$ e a competência liderança, a menor pontuação (74,9\%). Considerando os resultados das demais, vê - se certa estabilidade entre os valores (média 78,9\%). Com estes valores, observa-se que a empresa é comprometida, consegue resultados e cumpre suas metas de produção, porém, comparada com a competência agilidade e flexibilidade, ocorre a $2^{\mathrm{a}}$ menor pontuação (76,6\%).

Uma resposta a isso seria o desenvolvimento da competência liderança. $O$ desenvolvimento da competência liderança pode proporcionar ganhos em várias outras competências (CHUNG-HERRERA, ENZ e LANKAU, 2003). 


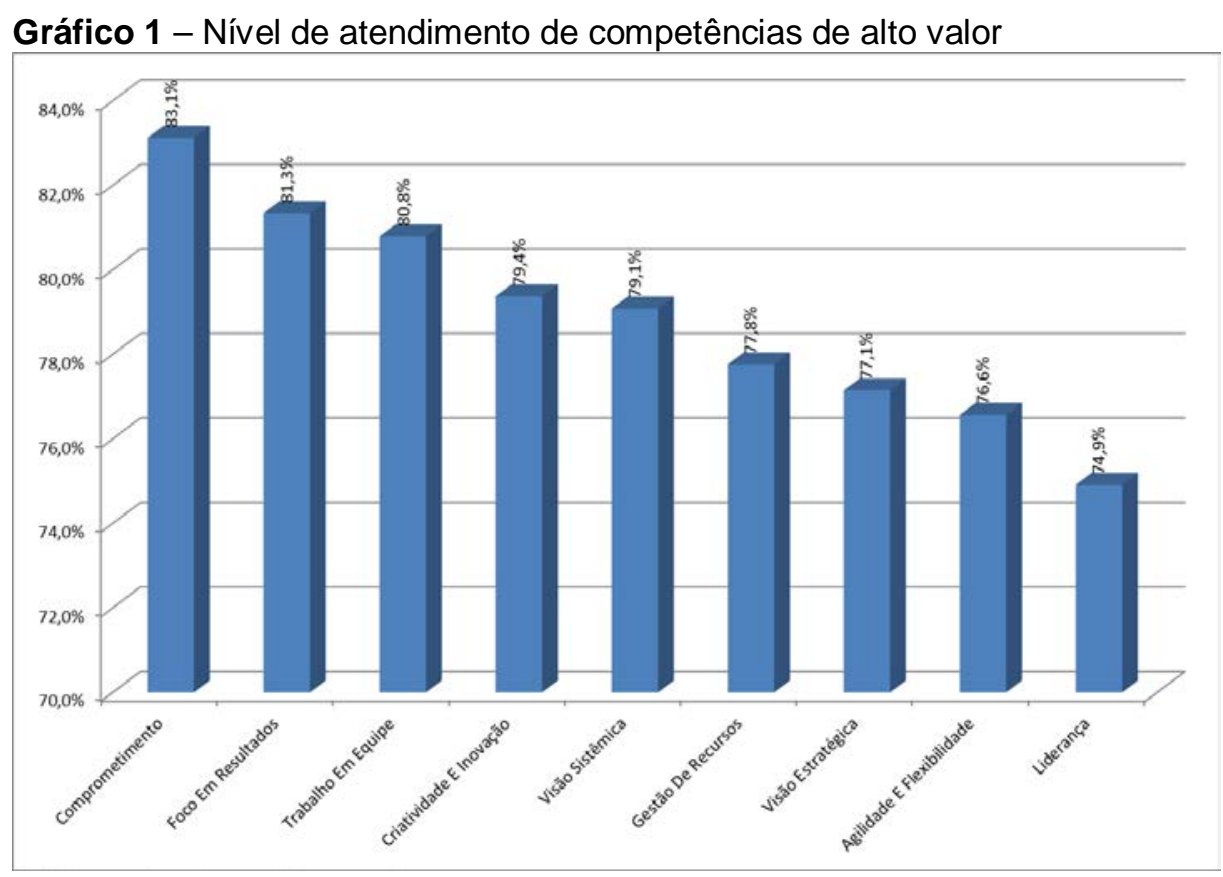

Para aumentar o nível de competências, são necessárias metodologias e aplicações específicas que ajudem a desenvolver competências que impactem o mercado. Os Executivos de uma empresa podem cultivar uma competência no planejamento estratégico, envolvendo-se em tal planejamento (GUIMARÃES et al, 2014). Acrescenta-se que as equipes de gestão precisam envolver-se na tomada de decisão estratégia. O desenvolvimento de uma competência no pensamento estratégico requer que gerentes seniores de linha tomem responsabilidade pessoal de desenvolver insights estratégicos que nortearão a empresa. Se as companhias fazem essas tarefas como uma parte integral de seu planejamento anual, os seus gestores se tornarão pensadores estratégicos competentes (CHRISTENSEN, 1997).

A tabela 1, a seguir, demonstra o nível de atendimento às competências por país de atuação. As pontuações médias foram consideradas em relação à escala Likert utilizada no questionário, sendo 1 a menor pontuação e 4 a maior pontuação para cada um dos comportamentos observáveis em cada competência (vide quadro 2 e quadro 3 respectivamente). 
Tabela 1 - Pontuação média das competências por país de atuação:

\begin{tabular}{lccc}
\hline \multicolumn{1}{c}{ Competência } & Brasil & México & Argentina \\
\hline Agilidade e Flexibilidade & 3,17 & 2,98 & 3,04 \\
Comprometimento & 3,62 & 3,08 & 3,28 \\
Criatividade E Inovação & 3,33 & 3,05 & 3,15 \\
Foco Em Resultados & 3,47 & 2,99 & 3,30 \\
Gestão de Recursos & 3,19 & 3,00 & 3,14 \\
Liderança & 3,21 & 2,68 & 3,10 \\
Trabalho em Equipe & 3,35 & 3,06 & 3,28 \\
Visão Estratégica & 3,25 & 2,79 & 3,22 \\
Visão Sistêmica & 3,31 & 2,82 & 3,36 \\
\hline
\end{tabular}

Fonte: Autores

Para mensurar a confiabilidade do instrumento de pesquisa, realizou-se a aplicação do coeficiente alfa de Cronbach.O alfa de Cronbach é uma ferramenta estatística que quantifica, numa escala de 0 a 1, a confiabilidade de um questionário. O valor mínimo aceitável para se considerar um questionário confiável é 0,7. A seguir tem-se a fórmula do coeficiente de Cronbach (LEONTITSIS e PAGGE, 2007):

$$
\alpha=\frac{\mathrm{k}}{\mathrm{k}-1}\left[\frac{\sigma_{\tau}^{2}-\sum_{\mathrm{i}=1}^{\mathrm{k}} \sigma_{\mathrm{i}}^{2}}{\sigma_{\tau}^{2}}\right]
$$

Sendo:

- k é o número de itens do questionário;

- $\sigma^{2} \mathrm{i}$ é a variância do i- ésimo item ( $\left.\mathrm{i}=1, \ldots, \mathrm{k}\right)$;

- $\sigma^{2} \tau$ é a variância do total $(\tau)$ j de cada indivíduo nos $\mathrm{k}$ itens;

Nos questionários aplicados nas Unidades de Fabricação Brasil, México e Argentina, temos os seguintes coeficientes apresentados na tabela 2: 
Tabela 2 - Coeficiente alfa de Cronbach aplicado

\begin{tabular}{|l|c|c|c|}
\cline { 2 - 4 } \multicolumn{1}{c|}{} & BRASIL & ARGENTINA & MÉXICO \\
\hline $\mathrm{k}$ & 9 & 9 & 9 \\
\hline $\mathrm{n}$ & 191 & 51 & 35 \\
\hline$\sigma^{2}$ & 1,94 & 3,73 & 7,04 \\
\hline$\sigma^{2} \tau$ & 9,91 & 24,73 & 24,74 \\
\hline $\boldsymbol{\alpha}$ de Cronbach & $\mathbf{0 , 9 0 4}$ & $\mathbf{0 , 9 5 5}$ & $\mathbf{0 , 8 0 4}$ \\
\hline
\end{tabular}

Conforme aplicação do coeficiente alfa de Cronbach, verifica-se que a confiabilidade do instrumento encontra-se em níveis propícios para sua aplicação.

Com a aplicação dos questionários, foi possível ampliar a visão do atendimento das competências por departamento, de modo que se vê um foco direcionado dependendo da competência mais exigida.

No Gráfico 2 a seguir, têm-se as competências divididas por departamentos, mas, especificamente, uma unidade de fabricação brasileira. Observa-se que a competência Visão Sistêmica é muito mais evidente na área de Logística, porém muito baixa em cargos de Gestão. Questiona-se se o gestor não consegue observar o restante dos processos e seus impactos na cadeia produtiva dentro da organização. Pode-se atribuir essa atitude ao sistema fechado em que cada gestor prioriza sempre sua área e/ ou departamento (FLEURY, FLEURY e BORINI, 2013).

Nota-se no gráfico a seguir, que a competência comprometimento atingiu valores significativos nessa unidade de avaliação, sendo essa competência valorizada em todos os níveis da organização.

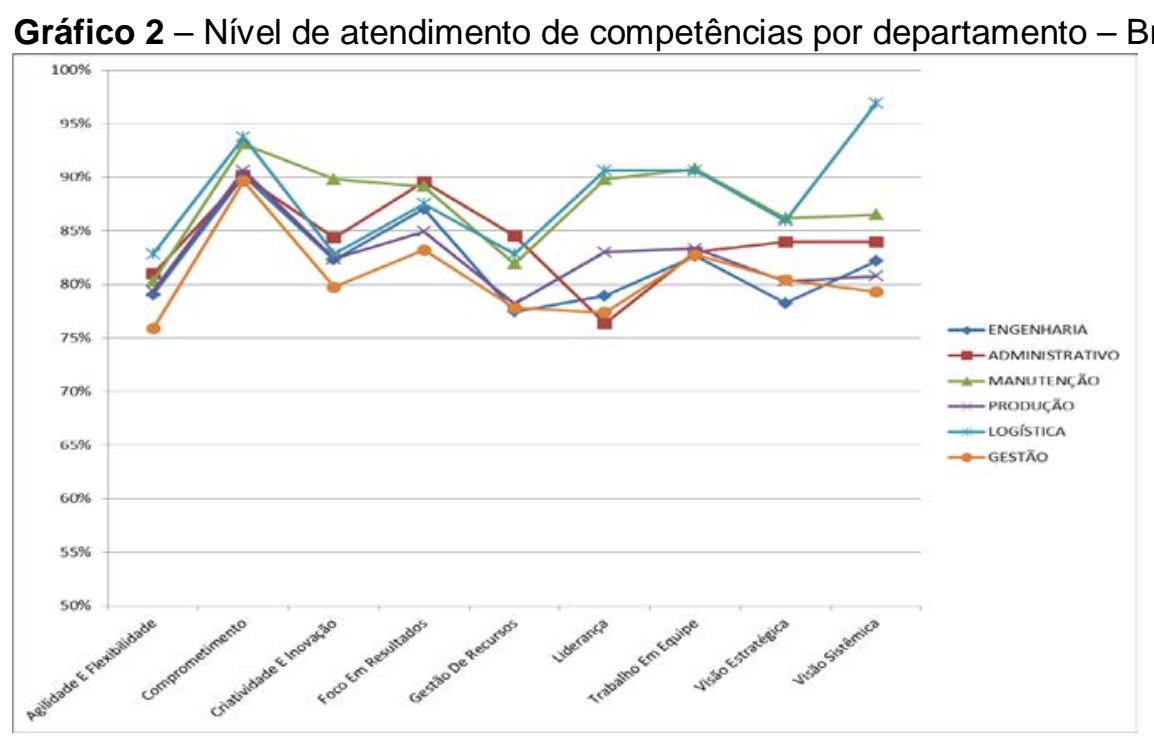

Revista Produção Online, Florianópolis, SC, v.16, n. 1, p. 151-181, jan./mar. 2016. 
Outro fato que chama a atenção no Gráfico 2 é o nível de atendimento da competência criatividade e inovação no setor de manutenção. Embora se acredite que setores de marketing e engenharia sejam preeminentes, nesta competência, conforme Balachandra e Friar (1997), porém, na empresa estudada, a manutenção é quem gera a maior parte das ideias e inovações tecnológicas, uma vez que este setor também é responsável pela automação de máquinas e equipamentos, cabendo à engenharia o apoio nos processos de produção.

O próximo gráfico considera o nível de atendimento de competências de alto valor para a unidade de fabricação no México:

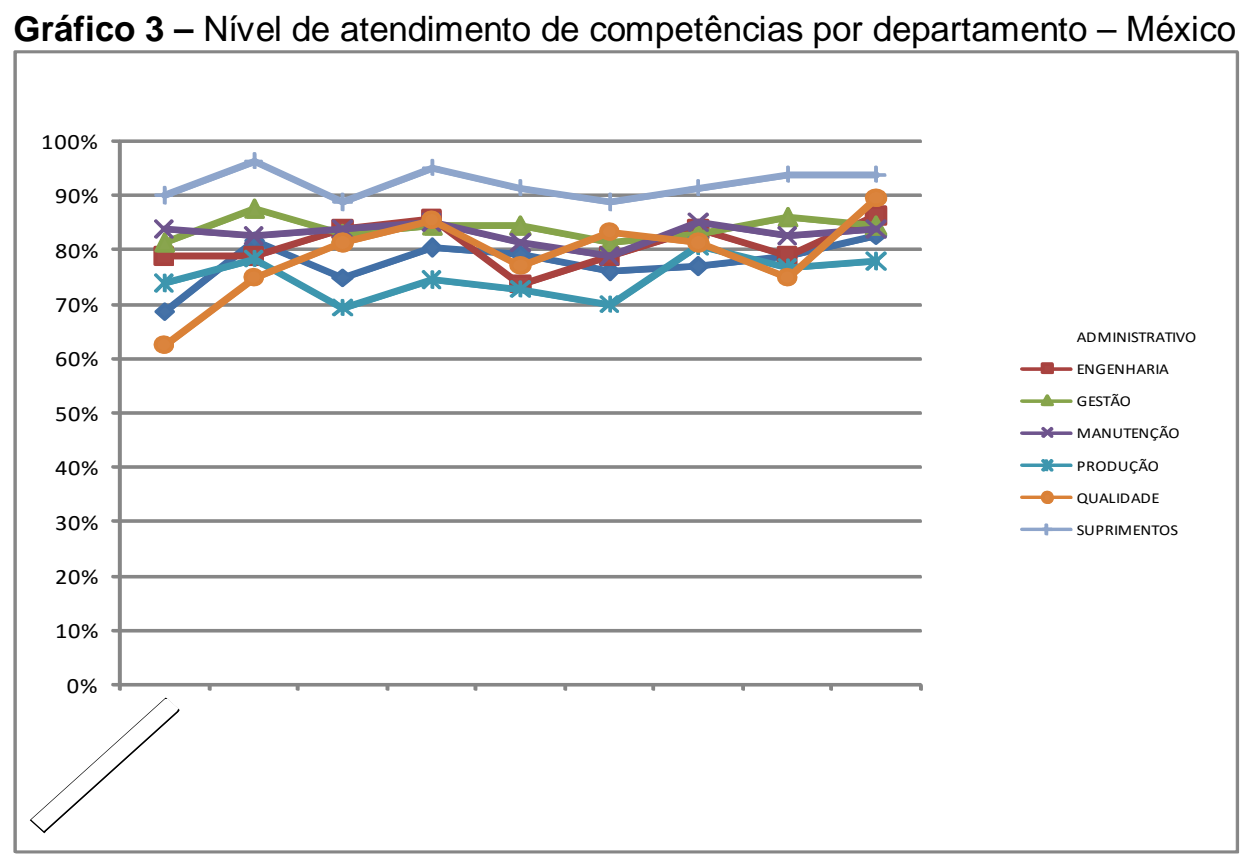

Observa-se, também, a prevalência da competência Visão Sistêmica agora para o departamento de Qualidade. A competência Trabalho em equipe foi muito mais valorizada no departamento de produção (fabricação) do que as demais competências.

No Gráfico 4, tem-se o nível de atendimento das competências de alto valor na terceira unidade de fabricação - Argentina: 


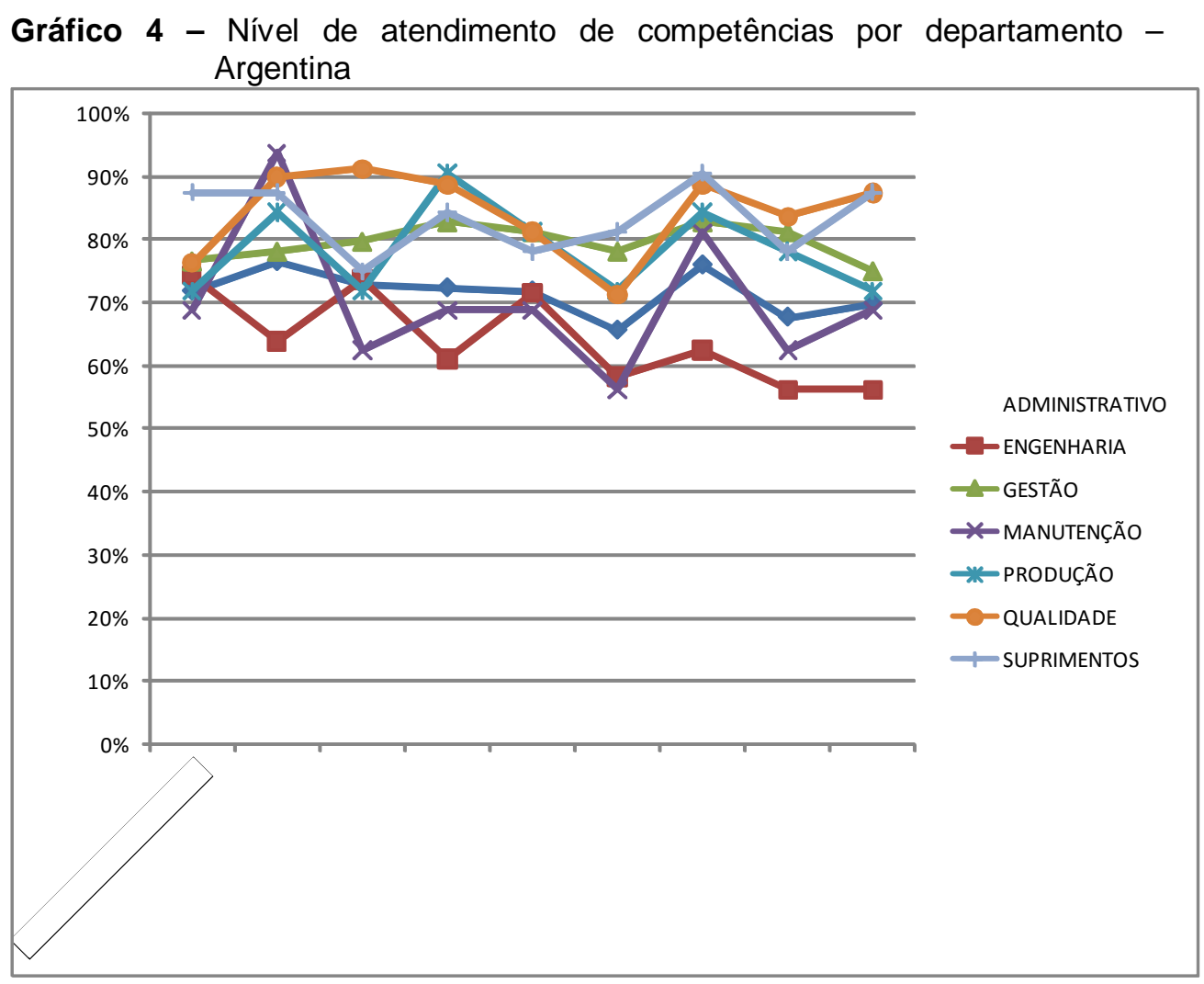

Nota-se, no Gráfico 4, uma valorização maior da competência Agilidade e flexibilidade por parte da Engenharia. Isso pode ser atribuído à velocidade de respostas aos projetos que são solicitados. Em consonância com os estudos de Christensen (1997), a competência visão estratégica ainda não é uma competência bem desenvolvida nos gestores, mostrando oportunidades de melhorias.

\section{CONSIDERAÇÕES FINAIS}

Vale ressaltar que a pesquisa possuiu algumas limitações. Devido a ela ser conduzida e realizada apenas por observadores dos comportamentos exibidos, a presente pesquisa poderia estender-se também ao avaliado, que contribuiria com sua visão pessoal a respeito de suas competências.

De uma forma geral, conseguiu-se atingir o objetivo proposto, pois, por intermédio do levantamento e questionamento das competências previamente definidas pela organização, conseguiu-se obter um panorama sobre o nível de atendimento delas. 
Ressalta-se que, para o alcance dos resultados, várias etapas precisaram ser cumpridas, a saber: o mapeamento das competências, a elaboração do questionário estruturado, a verificação da consistência interna do instrumento de pesquisa, e a análise e o tratamento dos dados que pudessem ser úteis aos gestores das unidades de produção estudadas.

Durante o processo de obtenção dos dados, alguns desafios surgiram, tais como: tempo de resposta (alguns respondentes extrapolaram o prazo inicial, necessitando de prorrogação do prazo), programação em software, instrução dos respondentes, entre outros. A maior dificuldade, porém, foi quanto à confidencialidade dos dados, uma vez que houve a necessidade de travar o software para que somente pessoas autorizadas pela organização pudessem ter acesso aos dados. A decisão foi necessária, pois alguns avaliadores sentiram - se desconfortáveis com a abertura das notas nominais a todos os participantes da pesquisa, por receio de gerar conflitos internos de interesses, a exemplo, expectativas de promoção ou similares.

Apesar dos desafios, a pesquisa proporcionou um direcionamento para a tomada de decisão dos gestores, pois, de posse das informações apresentadas, conseguiu-se observar os gaps (espaços) de competência nas unidades de produção e trabalhar no sentido de reduzi-los ao máximo. Outra vantagem proporcionada pela pesquisa foi a identificação dos ativos humanos mais estratégicos para a organização, uma vez que compreendem um maior atendimento às competências de alto valor.

Por fim, futuras pesquisas poderão ser elaboradas com base nas competências abordadas neste trabalho ou mesmo em outras, principalmente, nos assuntos referentes à correlação do nível de atendimento às competências frente ao nível de desempenho organizacional, gerando mais conhecimento e contribuições para gestores e pesquisadores na área de gestão por competências.

\section{REFERÊNCIAS}

\section{AJZEN, Icek. The Theory of Planned Behavior. Organizational Behavior and Human Decision Processes, v.50, p. 179-211, 1991.}

AMARAL et al. Modelo para o mapeamento de competências em equipes de inteligência competitiva. Ci. Inf., Brasília, v. 37, n. 2, p. 7-19, maio/ago. 2008. 
http://dx.doi.org/10.1590/S0100-19652008000200001

BASTOS, Antônio. V. B. Comprometimento organizacional: um balanço dos resultados e desafios que cercam essa tradição de pesquisa. Revista de Administração de Empresas, São Paulo, v. 33, p. 52-64, maio/jun. 1993. http://dx.doi.org/10.1590/S0034$\underline{75901993000300005}$

BALACHANDRA, R.; FRIAR, John. H. Factors for Success in R\&D Projects and New Product Innovation: A Contextual Framework. Transactions on Engineering Management, v. 44, n. 3, August 1997.

BERNARDONI, Doralice. Mapeamento de competências: um estudo de caso na próreitoria de pesquisa e pós-graduação da universidade federal do Paraná. Universidade Federal do Paraná, 2010.

BERTO, Rosa. M.V.S.; NAKANO, Davi. A Produção Científica nos Anais do Encontro Nacional de Engenharia de Produção: Um Levantamento de Métodos e Tipos de Pesquisa. Produção, v. 19. n. 2, p. 65-76. ABEPRO. Rio de Janeiro. 2000. http://dx.doi.org/10.1590/S0103-65132013005000007

BRANDÃO et al. Gestão de desempenho por competências: integrando a gestão por competências, o balanced scorecard e a avaliação 360 graus. Revista de Administração Pública, v. 42, p. 875-98, set./out. 2008. http://dx.doi.org/10.1590/S003476122008000500004

BRANDÃO, Hugo P.; BAHRY, Carla. P. Gestão por competências: métodos e técnicas para mapeamento de competências. Revista do Serviço Público, v. 56, p. 179-194, abr./jun. 2005.

BRANDÃO, Hugo P.; GUIMARÃES, Tomás. A. Gestão de competências e gestão de desempenho: tecnologias distintas ou instrumentos de um mesmo construto? RAE - Revista de Administração de Empresas, v. 41, n. 1, jan./mar. 2001. http://dx.doi.org/10.1590/S0034-75902001000100002

CARNEVALLI et al. Modularidade em montadoras de automóveis: uma análise sob a ótica da estratégia. Revista Produção Online. v.15, n. 2, p.433-457, abr./jun. 2015. http://dx.doi.org/10.14488/1676-1901.v15i2.1741

CHRISTENSEN, Clayton. M. Making Strategy. Harvard Business Review. November/December 1997.

CHUNG-HERRERA, Beth. G.; ENZ, Cath. A.; LANKAU, Melenie J. Grooming Future Hospitality Leaders: A Competencies Model. Cornell Hotel and Restaurant Administration Quarterly, June 2003

COVEY, Stephen. R. The 7 habits of highly effective people. Franklin Covey, 1989

DRAGANIDIS, Fotis.; MENTZAS, Gregoris. Competency based management: a review of systems and approaches. Information Management \& Computer Security, v. 14, n. , p. 51-64, 2006.

FERREIRA José I. A. X, Afonso. Como medir a competitividade das organizações. Revista Produção On line, v. 6, n. 2, ago. 2006. 
FLEURY, Afonso. Estratégias, organização e gestão de empresas em mercados globalizados: a experiência recente do Brasil. Gestão \& Produção, v.4, n.3, p. 264-277, dez. 1997. http://dx.doi.org/10.1590/S0104-530X1997000300002

FLEURY, Afonso.; FLEURY, Maria. T. Estratégias competitivas e Competências essenciais: Perspectivas para a Internacionalização da Indústria no Brasil. Gestão \& Produção, v.10, n.2, p.129-144, ago. 2003.

http://dx.doi.org/10.1590/S0104-530X2003000200002

FLEURY, Afonso; FLEURY, Maria T. L.; BORINI, Felipe M. The Brazilian Multinationals' Approaches to Innovation. Journal of International Management, v. 19, p. 260-275, 2013.

GUIMARÃES et al. Estratégia de produção na indústria de autopeças: estudo multicasos em empresas da região de Sorocaba. Revista Produção Online, v.14, n. 2, p. 499-532, abr./jun. 2014. http://dx.doi.org/10.14488/1676-1901.v14i2.1364

GÜNTHER, Harmut. Como elaborar um questionário (série: Planejamento de Pesquisa nas Ciências sociais, n. 01, Brasília, DF: UnB, Laboratório de Psicologia Ambiental, 2003

JORDAAN, Heila. Semantic processing skills of Grade 1 English language learners in two educational contexts. South African Journal of Education, v. 31, p. 518-534, 2011.

KAYAKUTLU, Gülgün.; BÜYÜKÖZKAN, Gülçin. Effective supply value chain based on competence success Supply Chain Management. An International Journal, v.15, n. 2, p.129-138, 2010.

LEONTITSIS, A.; PAGGE, J. A simulation approach on Cronbach's alpha statistical significance. Mathematics and Computers in Simulation. v. 73, p. 336-340, 2007.

LIMA, Edson P. L; LEZANA, Álvaro G. R. Desenvolvendo um framework para estudar a ação organizacional: das competências ao modelo organizacional. Gestão \& Produção, v.12, n.2, p.177-190, maio/ago. 2005.

http://dx.doi.org/10.1590/S0104-530X2005000200004

MACIEL, Cristiano O.; CAMARGO, Camila. Competências e Desempenho nas organizações varejistas: Um estudo na visão baseada em recursos. Revista Brasileira de Gestão de Negócios. v.11, n.32, p 308-321, jul./set. 2009.

MALMSTRÖM, Malin; WINCENT, Joakim; JOHANSSON, Jeaneth. Managing competence acquisition and financial performance: An empirical study of how small firms use competence acquisition strategies. J. Eng. Technol. Manage, v.30, p. 327-349, 2013.

MANTILLA, Mercedes; GARCÍA, Denys. Trabajo em equipos Autodirigidos: competências personales y conductas necesarias para su éxito. Revista Venezolana de Gerencia (RVG), v. 15, n. 49 , p. $51-71,2010$.

NONAKA, Ikujiro. The Knowledge-Creating Company. Harvard Business Review. July/August 2007.

PÉPIOT et al. A fuzzy approach for the evaluation of competences. Int. J. Production Economics, p. 336-353, 2008. 
SCHUMAN, H. ; KALTON, G. Survey Methods. Handbook of Social Psychology, V.1. p. 635-697, 1985.

SOUZA, Luciano. P.; FARIA NETO, Antonio; MUNIZ JR, Jorge. Análise crítica do processo de auditoria de sistema de gestão da qualidade no setor aeroespacial. Gest. Prod., v. 19, n. 1, p. 31-41. 2012. http://dx.doi.org/10.1590/S0104-530X2012000100003

SORDI, José. O.; CONTADOR, José. C. Integração dos sistemas de informação à estratégia da organização por meio do modelo de campos e armas da competição. R.Adm. v.40, n.2, p.123-135, abr./jun. 2005

TOLEDO et al. Fatores críticos de sucesso no gerenciamento de projetos de desenvolvimento de produto em empresas de base tecnológica de pequeno e médio porte. Gest. Prod., v. 15, n. 1, p. 117-134, jan./abr. 2008. http://dx.doi.org/10.1590/S0104-530X2008000100011

TORRES, Adriana A. L.; ZIVIANI, F.; SILVA, Sandro M. Mapeamento de competências: ferramenta para a comunicação e a divulgação científica. TransInformação, v. 24, p. 191205, set./dez., 2012.

http://dx.doi.org/10.1590/S0103-37862012000300004

VIEIRA, A.; GARCIA F. Gestão do conhecimento e das competências gerenciais: um estudo de caso na indústria automobilística. RAE-eletrônica, v. 3, n. 1, Art. 6, jan./jun. 2004. http://dx.doi.org/10.1590/S1676-56482004000100008

VILLARREAL, Julián P.; CERNA, Luís. M. Competencias directivas em escenarios globales. Estudos Gerenciales, v. 24, n. 109, p. 87-103, Octubre/Diciembre 2008.

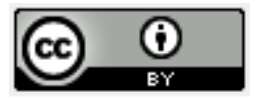

Artigo recebido em 23/04/2015 e aceito para publicação em 23/07/2015 DOI: http://dx.doi.org/ 10.14488/1676-1901.v16i1.2040 
AP ENDICE A - Resumos de estudos sobre competências

\begin{tabular}{|c|c|c|c|c|c|}
\hline $\mathrm{N}$ & Autor & Objetivo & Resultado & Método (5W1H) & Sugestão de Trabalhos futuros \\
\hline 01 & $\begin{array}{c}\text { Lima e } \\
\text { Lezana (2005) }\end{array}$ & $\begin{array}{l} \\
\text { Apresentar os } \\
\text { pressupostos } \\
\text { teóricos de um } \\
\text { framework de } \\
\text { referência que } \\
\text { possa ser utilizado } \\
\text { na construção de } \\
\text { modelos } \\
\text { organizacionais, } \\
\text { cujo objetivo } \\
\text { orienta-se ao } \\
\text { estudo da ação } \\
\text { organizacional nas } \\
\text { medidas da sua } \\
\text { estruturação, } \\
\text { implementação e } \\
\text { desempenho. }\end{array}$ & $\begin{array}{l}\text { Apresentação de um } \\
\text { framework que contribui na } \\
\text { exposição de uma nova } \\
\text { síntese de natureza teórica, } \\
\text { com a inclusão da dimensão } \\
\text { "espaço" no desenho do } \\
\text { 'framework' de referência, } \\
\text { incorporando o contexto da } \\
\text { ação organizacional como um } \\
\text { elemento na estruturação e } \\
\text { organização de tal ação. A } \\
\text { pesquisa também apresentou } \\
\text { um foco nas questões } \\
\text { relacionadas à forma, na qual } \\
\text { se observa uma intenção de } \\
\text { tratar elementos que possam } \\
\text { ser objeto de prescrição. A } \\
\text { pesquisa também trouxe a } \\
\text { utilização do conceito de } \\
\text { hipertexto como uma solução } \\
\text { para integrar as diferentes } \\
\text { dimensões, nas quais se } \\
\text { verifica o equacionamento de } \\
\text { alguns problemas verificados } \\
\text { nas estruturas matriciais, e } \\
\text { podendo-se trabalhar } \\
\text { hipoteticamente com 'n' } \\
\text { dimensões. }\end{array}$ & $\begin{array}{c}\text { O que: Apresentar um framework que possa } \\
\text { ser utilizado na construção de modelos } \\
\text { organizacionais. } \\
\text { Quem: Gestores } \\
\text { Quando: } 2005 \\
\text { Onde: literatura existente } \\
\text { Por que: Apresentar um framework para ser } \\
\text { utilizado como referência na construção de } \\
\text { modelos para a representação e explicação } \\
\text { da ação organizacional. } \\
\text { Como: pesquisa na literatura, o } \\
\text { estabelecimento de uma referência que } \\
\text { contivesse as diferentes dimensões } \\
\text { utilizadas para a análise dos sistemas } \\
\text { organizacionais. }\end{array}$ & $\begin{array}{l}\text { Desenvolvimento de estudos de } \\
\text { natureza normativa no que se } \\
\text { refere aos sistemas } \\
\text { organizacionais. }\end{array}$ \\
\hline
\end{tabular}

Revista Produção Online, Florianópolis, SC, v.16, n. 1, p. 151-181, jan./mar. 2016. 
(cont.)

\begin{tabular}{|c|c|c|c|c|c|}
\hline $\mathrm{N}$ & Autor & Objetivo & Resultado & Método (5W1H) & Sugestão de Trabalhos futuros \\
\hline 02 & $\begin{array}{l}\text { Brandão et al } \\
\quad(2008)\end{array}$ & $\begin{array}{c}\text { Avaliar a } \\
\text { percepção dos } \\
\text { funcionários de } \\
\text { uma instituição } \\
\text { financeira acerca } \\
\text { de um modelo de } \\
\text { gestão de } \\
\text { desempenho } \\
\text { baseado em } \\
\text { competências }\end{array}$ & $\begin{array}{l}\text { Percepção positiva dos sujeitos } \\
\text { pesquisados a respeito do seu } \\
\text { novo modelo de gestão do } \\
\text { desempenho. Os sujeitos da } \\
\text { pesquisa consideraram o } \\
\text { instrumento de avaliação } \\
\text { proposto (modelo de avaliação } \\
\text { baseado em competências) } \\
\text { mais eficaz, democrático e } \\
\text { participativo que o anterior } \\
\text { utilizado na organização } \\
\text { pesquisada. Sugerindo assim, } \\
\text { que os aprimoramentos } \\
\text { realizados no modeloajudaram } \\
\text { a reduzir as discrepâncias, } \\
\text { aumentou a participação dos } \\
\text { funcionários e melhorou a } \\
\text { percepção de justiça e } \\
\text { equidade por parte dos } \\
\text { entrevistados. }\end{array}$ & $\begin{array}{l}\text { O que: Avaliar a percepção dos funcionários } \\
\text { a respeito de um modelo de avaliação } \\
\text { baseado em competências. } \\
\text { Quem: Funcionários e Gestores } \\
\text { Onde: Empresa do setor financeiro } \\
\text { Quando: } 2004 \\
\text { Por que: Auxiliar a reformulação do modelo } \\
\text { de avaliação existente com a proposição de } \\
\text { novo modelo. } \\
\text { Como: Aplicação de questionários fechados } \\
\text { em nove unidades da empresa estudada, } \\
\text { perfazendo } 67,34 \% \text { da população. } \\
\text { Utilização de estatística descritiva. } \\
\text { Realização de análise fatorial, empregando- } \\
\text { se o método de fatoração dos eixos } \\
\text { principais (Principal Axis Factoring - PAF), } \\
\text { com rotação Promax. } \\
\text { Análise da consistência interna dos fatores } \\
\text { e análise de variância. }\end{array}$ & $\begin{array}{l}\text { Estudos que reflitamem que medida } \\
\text { as competências expressas pelas } \\
\text { pessoas explicam a variância dos } \\
\text { resultados organizacionais que } \\
\text { verifiquem a interdependência entre } \\
\text { indicadores de cada perspectiva de } \\
\text { desempenho do BSC (Balance } \\
\text { Score Card), e que avaliem a } \\
\text { contribuição da avaliação } 360 \text { graus } \\
\text { para o desenvolvimento de } \\
\text { competências. }\end{array}$ \\
\hline
\end{tabular}




\begin{tabular}{|c|c|c|c|c|c|}
\hline N & Autor & Objetivo & Resultado & Método $(5 \mathrm{~W} 1 \mathrm{H})$ & Sugestão de Trabalhos futuros \\
\hline 03 & $\begin{array}{c}\text { Maciel e } \\
\text { Camargo } \\
(2009)\end{array}$ & $\begin{array}{l}\text { Avaliar a influência } \\
\text { de diferentes } \\
\text { competências } \\
\text { sobre o } \\
\text { desempenho de } \\
\text { empresas de } \\
\text { pequeno porte. }\end{array}$ & $\begin{array}{l}\text { Apresentou evidências de que } \\
\text { a competência atendimento ao } \\
\text { consumidor é mais alta nas } \\
\text { empresas deste segmento e } \\
\text { que a competência de } \\
\text { integração das atividades em } \\
\text { controles informatizados é } \\
\text { mais baixa. } \\
\text { A análise de regressão múltipla } \\
\text { demonstrou que treinamento e } \\
\text { motivação dos colaboradores } \\
\text { são bem significativos para } \\
\text { explicar o desempenho. }\end{array}$ & $\begin{array}{l}\text { O que: Avaliar a influência das } \\
\text { competências sobre o desempenho. } \\
\text { Quem: Proprietários de pequenos varejos. } \\
\text { Onde: Micro empresas do setor varejista. } \\
\text { Quando: } 2007 . \\
\text { Por que: entender como as competências } \\
\text { influenciam no desempenho do negócio. } \\
\text { Como: Análise estatística de dados por meio } \\
\text { de survey para os dados primários. }\end{array}$ & $\begin{array}{l}\text { Reafirmar o potencial da Visão } \\
\text { Baseada em Recursos (VBR), para } \\
\text { explicação das fontes de vantagens } \\
\text { competitivas em relação a outras } \\
\text { fontes teóricas da literatura que } \\
\text { trata sobre estratégia. }\end{array}$ \\
\hline
\end{tabular}




\begin{tabular}{|c|c|c|c|c|c|}
\hline $\mathrm{N}$ & Autor & Objetivo & Resultado & Método (5W1H) & Sugestão de Trabalhos futuros \\
\hline 04 & $\begin{array}{c}\text { Kayakutlu e } \\
\text { Büyüközkan } \\
\text { (2010) }\end{array}$ & $\begin{array}{l}\text { Propor um quadro } \\
\text { de decisão } \\
\text { gerencial para } \\
\text { diferentes níveis da } \\
\text { cadeia de } \\
\text { suprimentos para } \\
\text { abordar a } \\
\text { importância } \\
\text { estratégica das } \\
\text { competências. }\end{array}$ & $\begin{array}{c}\text { Explicou um modelo de } \\
\text { desempenho por competências } \\
\text { que pode auxiliar os gestores } \\
\text { na identificação dos níveis de } \\
\text { competências e dos fatores de } \\
\text { sucesso para a eficácia do } \\
\text { gerenciamento de } \\
\text { suprimentos. }\end{array}$ & $\begin{array}{l}\text { O que: Propor um quadro de decisão } \\
\text { gerencial para auxiliar os gestores a } \\
\text { identificarem os níveis de competências. } \\
\text { Quem: Proprietários e gestores. } \\
\text { Onde: Empresas com funções de } \\
\text { suprimentos. } \\
\text { Quando: } 2010 . \\
\text { Por que: Auxiliar os gestores na } \\
\text { identificação dos níveis de competência. } \\
\text { Como: Por meio da utilização do Método } \\
\text { ANP (uma generalização do Método AHP } \\
\text { introduzido por Saaty, 1980). } \\
\text { Método de auxílio à decisão por } \\
\text { multicritérios, amplamente utilizado para } \\
\text { seleção de fornecedores e também para } \\
\text { medidas de desempenho. }\end{array}$ & $\begin{array}{l}\text { Pesquisas que abordem mais a } \\
\text { eficácia da cadeia de } \\
\text { abastecimento utilizando um } \\
\text { período maior para a obtenção dos } \\
\text { fatores e dos critérios, } \\
\text { considerando a dinâmica do } \\
\text { conhecimento e os } \\
\text { objetivos de desempenho } \\
\text { organizacional. }\end{array}$ \\
\hline
\end{tabular}




\begin{tabular}{|c|c|c|c|c|c|}
\hline $\mathrm{N}$ & Autor & Objetivo & Resultado & Método (5W1H) & Sugestão de Trabalhos futuros \\
\hline 05 & $\begin{array}{c}\text { Fleury, Fleury e } \\
\text { Borini (2013) }\end{array}$ & $\begin{array}{l}\text { Investigar as } \\
\text { razões da } \\
\text { expansão das } \\
\text { multinacionais } \\
\text { brasileiras no } \\
\text { ambiente } \\
\text { internacional onde } \\
\text { a inovação é } \\
\text { elemento - chave } \\
\text { de competitividade. }\end{array}$ & $\begin{array}{l}\text { Realização da análise fatorial } \\
\text { exploratória que sintetizou as } \\
\text { relações entre as variáveis de } \\
\text { competência organizacional, } \\
\text { identificando fatores comuns. }\end{array}$ & $\begin{array}{l}\text { O que: Investigação das competências das } \\
\text { empresas brasileiras em expansão no } \\
\text { cenário internacional. } \\
\text { Quem: Gestores e funcionários de } \\
\text { multinacionais brasileiras } \\
\text { Onde: Empresas do setor industrial. } \\
\text { Quando: } 2013 . \\
\text { Por que: obter respostas a respeito do } \\
\text { questionamento da exigência da inovação } \\
\text { no mercado externo, visto a expansão das } \\
\text { multinacionais brasileiras que raramente } \\
\text { são tratadas como inovadoras. } \\
\text { Como: Survey aplicado em } 61 \\
\text { multinacionais brasileiras. }\end{array}$ & $\begin{array}{l}\text { Pesquisas que expliquem ainda } \\
\text { mais a relação da exigência da alta } \\
\text { qualidade, o que pode ser um fator } \\
\text { de desenvolvimento da } \\
\text { competência de inovar antes de } \\
\text { ocorrer a internacionalização. }\end{array}$ \\
\hline
\end{tabular}




\begin{tabular}{|c|c|c|c|c|c|}
\hline $\mathrm{N}$ & Autor & Objetivo & Resultado & Método (5W1H) & Sugestão de Trabalhos futuros \\
\hline 06 & $\begin{array}{c}\text { Brandão e } \\
\text { Guimarães } \\
\text { (2001) }\end{array}$ & $\begin{array}{c}\text { Discutir a } \\
\text { evolução, as } \\
\text { características e as } \\
\text { aplicações práticas } \\
\text { da gestão por } \\
\text { competências e da } \\
\text { gestão do } \\
\text { desempenho. }\end{array}$ & $\begin{array}{l}\text { Percepção da relação de } \\
\text { interdependência entre a } \\
\text { gestão de desempenho e a } \\
\text { gestão de competências. } \\
\text { Mostrou-se que mais que } \\
\text { tecnologias independentes ou } \\
\text { distintas, a gestão de } \\
\text { competências e a } \\
\text { de desempenho parecem } \\
\text { complementar-se em um } \\
\text { contexto mais amplo de gestão } \\
\text { organizacional. }\end{array}$ & $\begin{array}{l}\text { O que: Discutir as características da gestão } \\
\text { por desempenho e da gestão por } \\
\text { competências. } \\
\text { Quem: Literatura. } \\
\text { Onde: Organizações de diversos setores. } \\
\text { Quando: } 2001 . \\
\text { Por que: Auxiliar as organizações no que } \\
\text { tange ao desafio de desenvolver e utilizar } \\
\text { instrumentos de gestão que lhes garantam } \\
\text { certo nível de competitividade atual e futuro. } \\
\text { Como: Propor uma nova abordagem } \\
\text { conceitual que procure considerar a relação } \\
\text { de interdependência entre esses modelos de } \\
\text { gestão. }\end{array}$ & $\begin{array}{c}\text { Necessidade de aplicação } \\
\text { concomitante dos pressupostos } \\
\text { dos processos subjacentes a } \\
\text { ambos os instrumentos para } \\
\text { integrar e direcionar esforços, } \\
\text { sobretudo os relacionados à gestão } \\
\text { de recursos humanos. }\end{array}$ \\
\hline
\end{tabular}




\begin{tabular}{|c|c|c|c|c|c|}
\hline$N$ & Autor & Objetivo & Resultado & Método $(5 \mathrm{~W} 1 \mathrm{H})$ & $\begin{array}{c}\text { Sugestão } \\
\text { Trabalhos futuros }\end{array}$ \\
\hline 07 & $\begin{array}{l}\text { Pépiot et al } \\
\text { (2008) }\end{array}$ & $\begin{array}{c}\text { Propor uma } \\
\text { abordagem } \\
\text { metodológica para } \\
\text { a avaliação de } \\
\text { competências e a } \\
\text { integração dos } \\
\text { diferentes pontos } \\
\text { de vista existentes } \\
\text { na literatura. }\end{array}$ & $\begin{array}{l}\text { O método proposto permitiu a } \\
\text { integração das variáveis } \\
\text { linguísticas e sua } \\
\text { transformação em dados } \\
\text { numéricos que podem ser } \\
\text { utilizados para uma } \\
\text { determinação quantitativa das } \\
\text { competências. Além disso, a } \\
\text { proposta baseada na } \\
\text { metodologia fuzzy trouxe uma } \\
\text { flexibilidade suficiente para } \\
\text { incorporar critérios adicionais } \\
\text { que foram combinados de } \\
\text { várias maneiras, os quais } \\
\text { podem afetar } \\
\text { significativamente a avaliação } \\
\text { da competência. }\end{array}$ & $\begin{array}{l}\text { O que: Mostrar a importância das } \\
\text { competências para as decisões estratégicas } \\
\text { da empresa. } \\
\text { Quem: Engenheiros. } \\
\text { Onde: Indústria do setor ferroviário. } \\
\text { Quando: } 2008 . \\
\text { Por que: Buscar uma vantagem competitiva, } \\
\text { levando-se em conta não só o aspecto } \\
\text { operacional e a importância tática e } \\
\text { estratégica de cada competência, bem como } \\
\text { a disponibilidade de competências dentro e } \\
\text { fora da empresa e a dificuldade em transferi- } \\
\quad \text { las. } \\
\text { Como: Aplicação da lógica fuzzy nos } \\
\text { critérios e indicadores de desempenho. }\end{array}$ & $\begin{array}{c}\text { Novas abordagens para a definição } \\
\text { de critérios, regras e parâmetros } \\
\text { para utilização da metodologia } \\
\text { fuzzy. }\end{array}$ \\
\hline
\end{tabular}




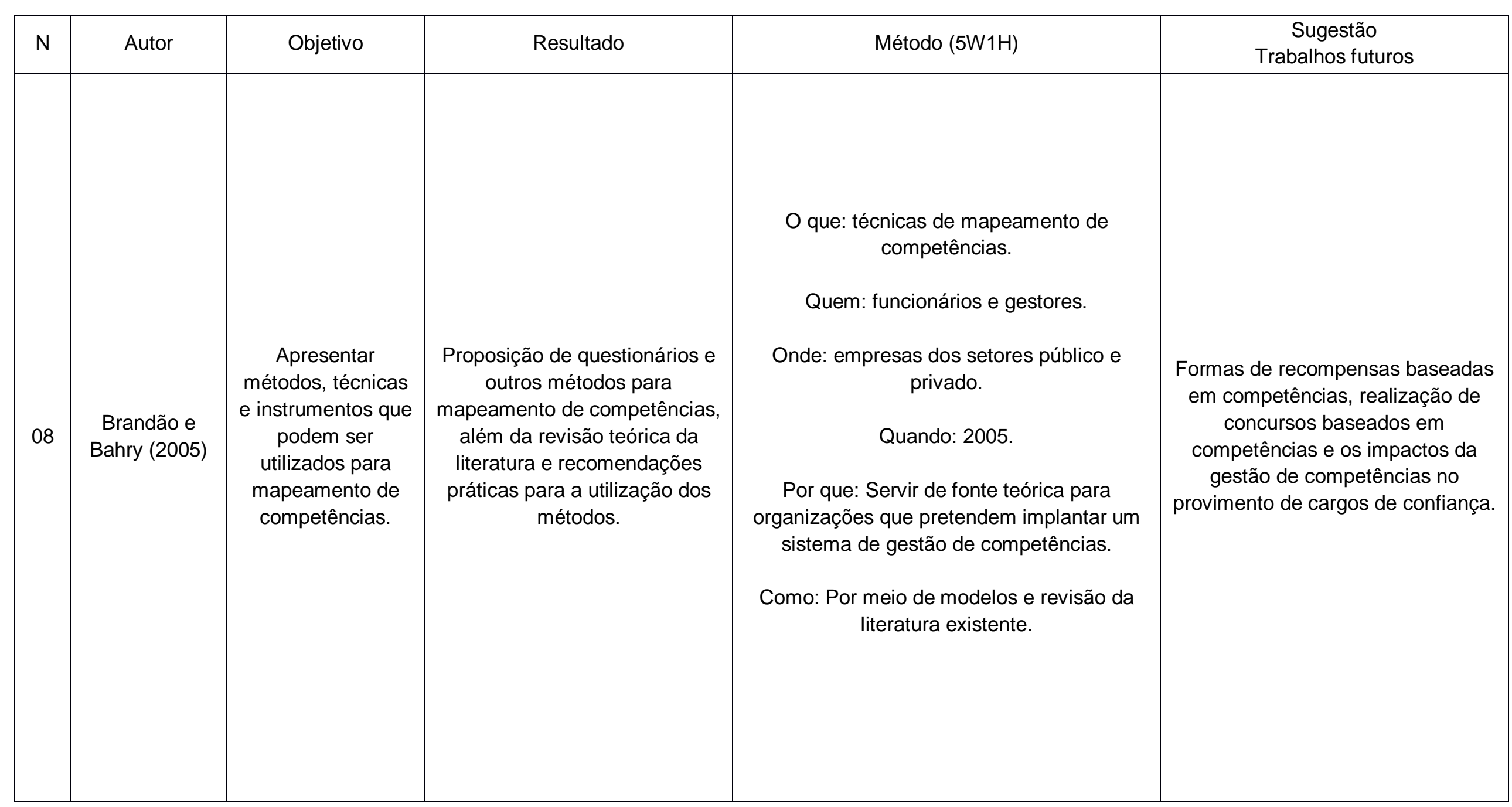

Revista Produção Online, Florianópolis, SC, v.16, n. 1, p. 151-181, jan./mar. 2016. 
(cont.)

\begin{tabular}{|c|c|c|c|c|c|}
\hline $\mathrm{N}$ & Autor & Objetivo & Resultado & Método (5W1H) & $\begin{array}{c}\text { Sugestão } \\
\text { Trabalhos futuros }\end{array}$ \\
\hline 09 & $\begin{array}{c}\text { Christensen } \\
\text { (1997) }\end{array}$ & $\begin{array}{l}\text { Apresentar uma } \\
\text { metodologia que } \\
\text { os executivos } \\
\text { podem empregar e } \\
\text { implementar, } \\
\text { cultivando uma } \\
\text { competência em } \\
\text { pensamento } \\
\text { estratégico e } \\
\text { compreender a } \\
\text { relação das } \\
\text { decisões } \\
\text { estratégicas com o } \\
\text { mercado }\end{array}$ & $\begin{array}{c}\text { O artigo demonstrou que } \\
\text { competências estratégicas } \\
\text { bem desenvolvidas podem } \\
\text { contribuir significativamente na } \\
\text { execução dos planos } \\
\text { operacionais, preparando os } \\
\text { gestores a agirem mais } \\
\text { eficazmente diante dos } \\
\text { desafios impostos pelo } \\
\text { mercado. } \\
\text { O desenvolvimento de } \\
\text { competências estratégicas } \\
\text { também contribuem para o } \\
\text { engajamento das equipes na } \\
\text { elaboração da estratégia } \\
\text { organizacional. }\end{array}$ & $\begin{array}{l}\text { O que: Método que visa desenvolver } \\
\text { competências em pensamento estratégico. } \\
\text { Quem: Gestores. } \\
\text { Onde: Empresa do ramo de tecidos. } \\
\text { Quando: } 1997 . \\
\text { Por que: Fornece um estudo de caso que } \\
\text { mostra por que os esforços dos gestores } \\
\text { seniores em fazer estratégia muitas vezes } \\
\text { revelam-se difíceis e ineficazes e como } \\
\text { estas dificuldades podem ser superadas. } \\
\text { Como: Realização de estudo de caso na } \\
\text { maior indústria européia de tecidos } \\
\text { revestidos e laminados. }\end{array}$ & $\begin{array}{l}\text { Terceirização do planejamento e os } \\
\text { fatores que impactam os gestores } \\
\text { seniores no desenvolvimento de } \\
\text { competências. }\end{array}$ \\
\hline
\end{tabular}




\begin{tabular}{|c|c|c|c|c|c|}
\hline N & Autor & Objetivo & Resultado & Método $(5 \mathrm{~W} 1 \mathrm{H})$ & $\begin{array}{c}\text { Sugestão } \\
\text { Trabalhos futuros }\end{array}$ \\
\hline 10 & $\begin{array}{c}\text { Malmström, } \\
\text { Wincent e } \\
\text { Johansson (2013) }\end{array}$ & $\begin{array}{c}\text { Identificar } \\
\text { estratégias de } \\
\text { gestão de } \\
\text { aquisição de } \\
\text { competência e } \\
\text { suas implicações } \\
\text { para o } \\
\text { desempenho. }\end{array}$ & $\begin{array}{l}\text { Consideração não só do uso } \\
\text { de estratégias de aquisição } \\
\text { de competências por parte } \\
\text { das pequenas empresas, bem } \\
\text { como de sua capacidade de } \\
\text { melhorar o desempenho de } \\
\text { suas ações. }\end{array}$ & $\begin{array}{l}\text { O que: Identificação de estratégias de } \\
\text { aquisição de competências. } \\
\text { Quem: Empresários e gestores. } \\
\text { Quando: } 2013 . \\
\text { Onde: Pequenas empresas dos setores do } \\
\text { conhecimento, eletrônicos e comércio. } \\
\text { Por que: Demonstrar que as pequenas } \\
\text { empresas, assim como as grandes } \\
\text { organizações, podem utilizar-se de } \\
\text { estratégias adequadas para a aquisição } \\
\text { de competências para melhoria do } \\
\text { desempenho organizacional. } \\
\text { Como: Envio de questionários aos CEOs e } \\
\text { Gestores das empresas, com envio de } \\
\text { número de série para preservar o } \\
\text { anonimato das respostas. }\end{array}$ & $\begin{array}{l}\text { Utilização de estratégias de } \\
\text { aquisição de competências em } \\
\text { outros ramos de atuação das } \\
\text { pequenas empresas. }\end{array}$ \\
\hline
\end{tabular}

Revista Produção Online, Florianópolis, SC, v.16, n. 1, p. 151-181, jan./mar. 2016. 